\title{
Light and Scanning Electron Microscope Studies of the Tongue of the Egyptian Mongoose (Herpestes ichneumon) \\ Atteyat Selim ${ }^{* 1}$ and Rania Samir ${ }^{2}$ \\ ${ }^{1}$ Zoology Department, Faculty of Science, Tanta University, Egypt \\ ${ }^{2}$ Faculty of Medicine, Tanta University, Egypt
}

*Corresponding author: Atteyat S, Zoology Department, Faculty of Science, Tanta University, Egypt, Tel: 02-040-3303691; E-mail: atteyatselim@hotmail.com

Received date: December 29, 2017; Accepted date: February 19, 2018; Published date: February 27, 2018

Copyright: ( 2018 Selim A, et al. This is an open-access article distributed under the terms of the Creative Commons Attribution License, which permits unrestricted use, distribution, and reproduction in any medium, provided the original author and source are credited.

\begin{abstract}
The lingual papillae of (Herpestes ichneumon) have specialized shapes different from other carnivore mammals. So, the present study aims to demonstrate those specialized papillae. We observed that the external surface of the tongue has different papillae (filiform, fungiform, and circumvallate). The tongue was elongated; their two-third width was almost fixed. Numerous filiform papillae were distributed along the anterior two-thirds of the tongue while the fungiform papillae were distributed between the filiform ones. There are different types of filiform papillae which are serrate, smooth small and giant elongated. The conical papillae appear toward the posterior end of the tongue. The fungiform papillae have different shapes from small to large beginning from the anterior apex to the posterior. We observed the circumvallate papillae at the posterior surface. Also groups of mucus glands present. Conclusion: Herpestes ichneumon, have specialized shapes different from other carnivore mammals.
\end{abstract}

Keywords: Tongue; Filiform; Fungiform; Circumvallate papillae; Mammals; Herpestes ichneumon

\section{Introduction}

The dorsal surface of tongue of mammals characterized by different types of papillae which have different distributions according to the food intake, in mammals, the taste buds have receptor cells located on certain papillae [1].

Many previous authors describe the tongue of bats especially insectivorous species [2-5] and others fructivorous [6-8]. All of them observed two types of mechanical papillae (i.e. filiform and conical) and two types of gustatory papillae for taste perception.

In some nectar eating species protractile tongues are present. There are mechanical papillae in the form of brush on the apex of the tongue [9].

The mammalian animals have different species with morphological diversity depends on the dietary habits and their living environment $[10,11]$.

In carnivore animals numerous filiform papillae Common raccoon, Procyonlotor were distributed along the fungiform one which distributed between them. Eight vallate papillae that had a weak circumferential ridge were distributed in a V-shape in the posterior part of the tongue and numerous taste buds were observable in the circumferential furrows of vallate papillae [12].

The tongues and their lingual papillae of the mammalian animals show morphological variations, which depends on the evolutions, taxonomy of mammalian species and also influenced by the environment in which the mammals live, such as watery or land. The Carnivore animals are widely distributed and are traditionally divided at the suborder level into carnivores, dog-like carnivores, and cat-like carnivores. Dog-like carnivores, [13,14].
In mammals, the tongue plays important role in feeding such as collecting solutions, taste of food and swallowing it.

Nearly all mammalian animals have the same type of papillae, filiform, fungiform and foliate or circumvallate papillae but there is major difference on the subtype of filiform ones.

So, the paper aims to describe the different types of lingual papillae which present in the tongue of the carnivore Egyptian Herpestes ichneumon in order to find the difference between the carnivore and the other previous ones.

\section{Materials and Methods}

Ten tongues of each of the adult carnivore Herpestes ichneumon, family Viverridae, collected from Abu-Rawash, Giza were used in the present study. The tongues collected immediately after killed the animals. Samples for scanning electron microscope, histological and histochemical observations were taken from the apex, the body and the root of the tongue. Samples immediately fixed in Bouin's fluid and 10\% neutral buffered formalin for 24 hours. The tissue samples were dehydrated in ascending grades of ethyl alcohol, cleared by xylene and embedded in paraffin. Sections of $5 \mu$ thickness were mounted and stained with Haematoxylin and Eosin method [15]. All preparations were microscopically examined for the histological examination.

\section{Histochemical examination}

Periodic acid Schiff procedure (PAS): Sections were treated by Periodic Acid Schiff procedure (PAS). This comprised placing the sections in $0.5 \%$ periodic acid for 5-10 minutes, washing for 5 minutes in running tap water, then rinsed in distilled water and treated with Schiff's reagent for 20-35 minutes. Sections were passed through 3 changes of freshly prepared $\mathrm{M} / 20$ sodium acid sulphite solution, two minutes in each. They were washed in tap water for 5 minutes, and then rinsed in distilled water. Dehydration was carried out in 
ascending series of ethyl alcohols, cleared in xylene and mounted in Canada balsam.

The PAS reaction is based on the oxidation of the glycol linkages in polysaccharides by periodic acid, thus producing aldehydes. These liberated aldehydes react with the leuco fuchsin of Schiff's reagent producing a compound of a magenta color.

The PAS reaction used to: demonstrate the mucous secretion of the goblet cell and the duodenal gland of both duodenum and ileum, differentiate mucous gland from serous gland of the tongue, and differentiate acidophilic from basophilic cells of the pituitary gland.

Azan stain: Sections were treated by xylene for 20 minutes to remove the wax, hydration was carried out in descending series of ethyl alcohols, then put in aniline alcohol for 45 minutes, washed in acid alcohol for 1 minute, put in azocarmine for an hour at 56c, then washed in acid alcohol and distilled water, put in phosph-molybedate for 2-3 hours, washed in distilled water, put in aniline blue for an hour, washed in distilled water, put in phosph-molybedate, then in acid alcohol. Dehydration was carried out in ascending series of ethyl alcohol, cleared in xylene and mounted in Canada balsam [16]. Azan stain used to: demonstrate the muscles, the connective tissue and the serous gland if present of the tongue.

\section{Electron microscopy}

While fixed in Glutarldhyde for Scanning then dehydrated in a series of ethanol, mounted on aluminum stubs, covered with carbon tape, sputtered with gold and examined on an SEM. The whole tongue was photo (pictured) by specialized camera under ruler for macroscopic observations [17].

\section{Statistical analysis}

All data were expressed as means for eight to ten animals \pm SD. Data were tested by F-test. Student's t-test was used to compare the mean value. The minimum level of statistical significance was set at p0.05. The methods used for the analysis of the results are that described by Snedecor and Cochron [18].

Statistical presentation and analysis of the present study was conducted, using the mean, standard deviation, by SPSS.

Mean value $(\bar{X})$ : the sum of all observations divided by the number of observation: $(\bar{X})=\frac{\Sigma x}{n}$
Where $(\bar{X})=$ mean value. $\Sigma x=$ The sum of individual observations $\mathrm{n}=$ number of observations.

2-Standrd Deviation [SD]:

It measures the degree of scatter of individual varieties around their mean:

$$
S D=\sqrt{\frac{\sum|\mathrm{x}-\mathrm{x}|^{-2}}{n-1}}
$$

Where $\sum(x-x)^{2}$, is the sum of squares of the difference between each observation (X) and the mean value of all observations (X).

\section{Results}

\section{Macroscopic overview}

Macroscopically, the tongue of Herpestes ichneumon is elongated, divided into three parts: the lingual apex, lingual body and lingual root. The median sulcus of the tongue was not visible in the midline of the tongues. The anterior end is curved not pointed that happened in other mammals (Figure 1 and Table 1).

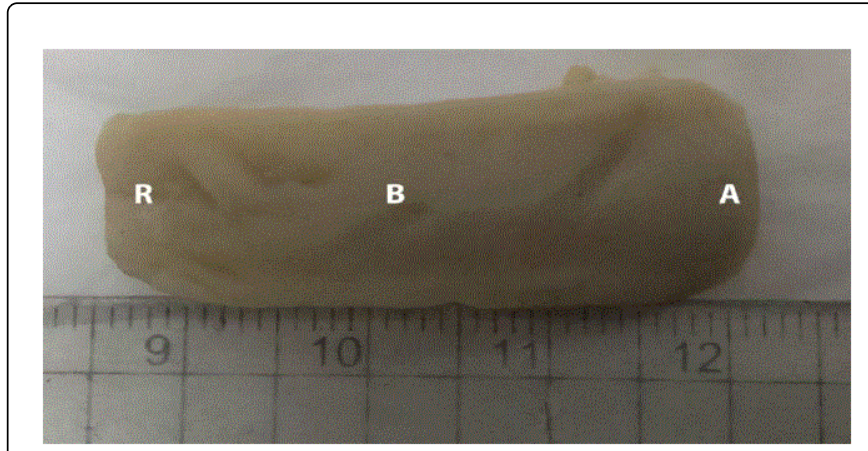

Figure 1: Overview of the whole mount of Herpestes ichneumon. The tongue is divided into three parts, the anterior part (A) is curved larger than the body part (B) and the root.

\begin{tabular}{|l|l|l|l|l|l|l|l|l|l|}
\hline Tongue length & First & Second & Third & Fourth & Fifth & Sixth & Seventh & Eight & Ninth \\
\hline & 3.4 & $3.3 \mathrm{~cm}$ & $3.1 \mathrm{~cm}$ & 3.2 & 3.5 & 3.6 & 3.7 & 3 & 3.2 \\
\hline Mean & $3.3 \pm 0.05$
\end{tabular}

Table 1: Histogram showing the measurement of the tongues of ninth specimens of Herpestes ichneumon (cm).

\section{Histological and histochemical observation}

The ventral surface of the tongue covered by stratified keratinized squamous epithelium with lamina properia and blood capillaries present (Figure 2). The filliform papillae covered the anterior part of the dorsal surface of the tongue, appearing as small finger-like projections with rounded or blunted tips; some of them had started to have a conical appearance. The periphery of filliform papilla coated by a thin keratinized epithelium, Keratinization is clearly observed at the tips of each filliform papillae. The entire core of the papillae was formed of a fine collagen network and fibroblasts. 

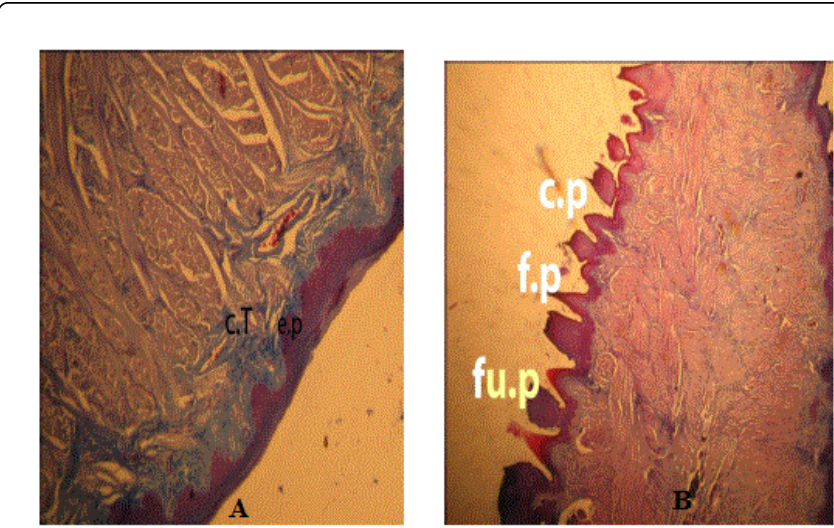

Figure 2: Transverse sections of the tongue of Herpestes ichneumon, the different types of papillae at the dorsal surface of the tongue 100 a) showing the ventral surface e.p Epithelium and c.t connective tissue azan stain X 400 b) C .p conical papillae, f.p filiform papillae and fu.p fungiform azan stain X 100.
At the posterior end observed the mucus glands give strong reaction with periodic acid Schiff (PAS) (Figures 3 and 4).
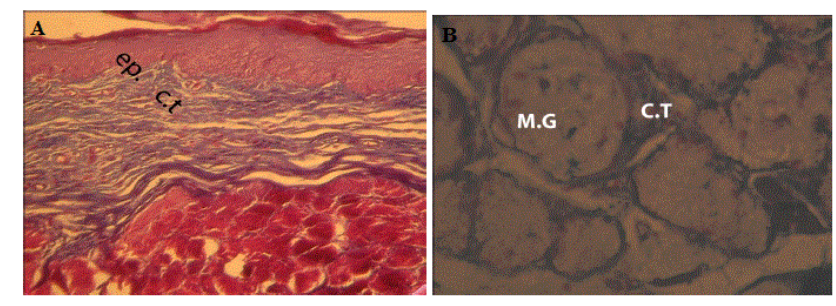

Figure 3: Transverse sections of the tongue of Herpestes ichneumon showing the ventral surface of the tongue e.p Epithelium (A) and the mucus glands (M.G), (c.t) connective tissue azan stain X 400 (B).
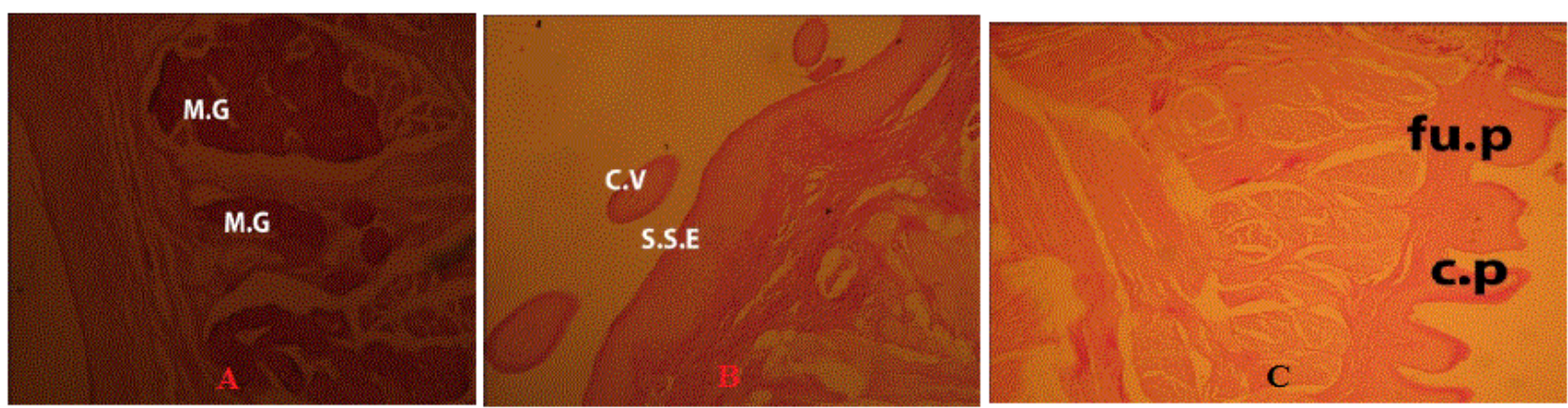

Figure 4: Transverse sections of the tongue of Herpestes ichneumon showing a) mucous gland (M.G) give strong reaction with PAS ) stain $\mathrm{X} 400$ and b) showing the circumvallate papille (c.v) and stratified squamous epithelium (s.s.e) fungiform and conical papillae (C.P) periodiac acid Schiff (PAS) stain X400.

\section{Ultra structure observations}

At the apex of the tongue appear fungiform papillae Dum in shape and numbers of filiform papillae with different shapes as small serrate and smooth elongated filiform ones (Figure 5).

Each papillae has one major conical process covered with keratinized small process. The median sulcus of the tongue was not visible in the midline of the tongues. The fungiform papillae scattered among the filiform ones at the apex of the tongue (Figure $5 a$ and $5 b$ ).

At the anterior median part there are large number of smooth small filiform papillae and serrate small filiform papillae (Figure 5c-5e). The external surface of fungi form papillae distributed on the anterior apex of tongue which were smooth and dome-like (Figure $5 a$ and $5 b$ ).

Toward the posterior middle part of the tongue the giant elongated filiform papillae and smooth filiform appear again with fungiform papillae scattered between them (Figure 6a-6d), also the fungiform appear. The large conical filiform papillae and the conical papillae have different shape (Figure 6e and 6f).
At the posterior root of the tongue there are large conical papillae, smooth conical and small serrate filiform appear again (Figure 7a-7d). Also there are circumvallate papillae with bifid process that have different shape from the other animals (Figure 7e-7g).

The elongated tongue of the Egyptian Mongoose (Herpestes ichneumon) has flat surface and free anterior part in order to facilitate it to swallowing the body of its animals which feed with it but in the Egyptian bat the tongue is used to swiping the extract from the fruit so it appear pointed [19].

In this study, we observed various aspects of the lingual papillae of the (Herpestes ichneumon). The tongue had each of the following lingual papillae: serrate, elongated and conical filiform papillae, also fungiform and circumvallate papillae. We observed the filiform papillae identical with those of the Common raccoon i.e. it consists of main protrusions that were covered with several small processes. The similar morphology of filiform papillae between the Raccoon dog and Common raccoon might be representative of an omnivorous-like diet [12]. 
Citation: Selim A, Samir R (2018) Light and Scanning Electron Microscope Studies of the Tongue of the Egyptian Mongoose (Herpestes ichneumon). J Cytol Histol 9: 499. doi:10.4172/2157-7099.1000499
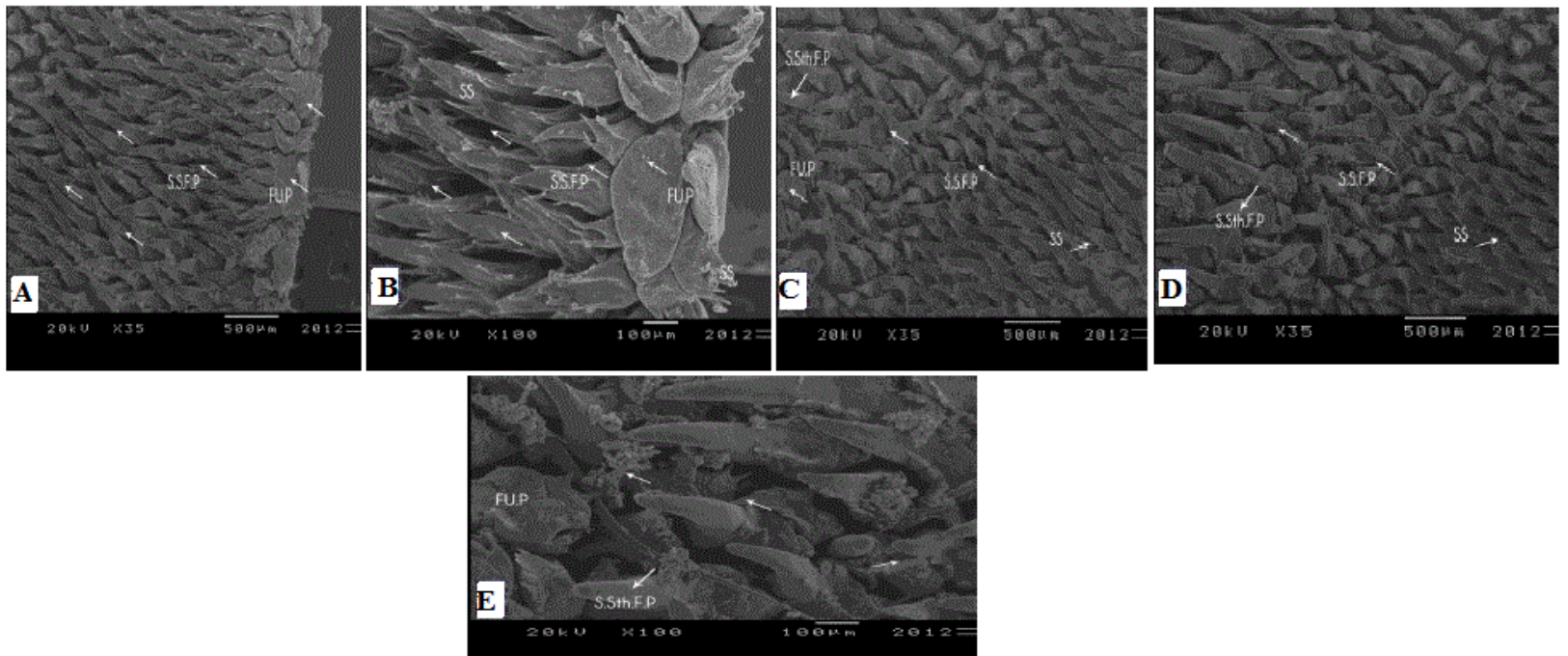

Figure 5: A set of lingual papillae distributed on the apex (a) part of the tongue. a: scanning electron micrograph of fungiform papillae distributed on the apex of tongue (Fu.P), and small serrate filiform papillae (S.S.F.P) indicated as arrows were observable on the top of the tongue b: Scanning electron micrograph of the external surface of fungiform papilla with higher magnification situated on the apical part of tongue. $\mathrm{C}$ and d: SEM micrograph showing the smooth elongated (Sth.F.P) filiform papillae within the serrate filiform ones .E. show the fungiform papillae (FU.P) and the Smooth small filiform papillae (S.Sth.P).

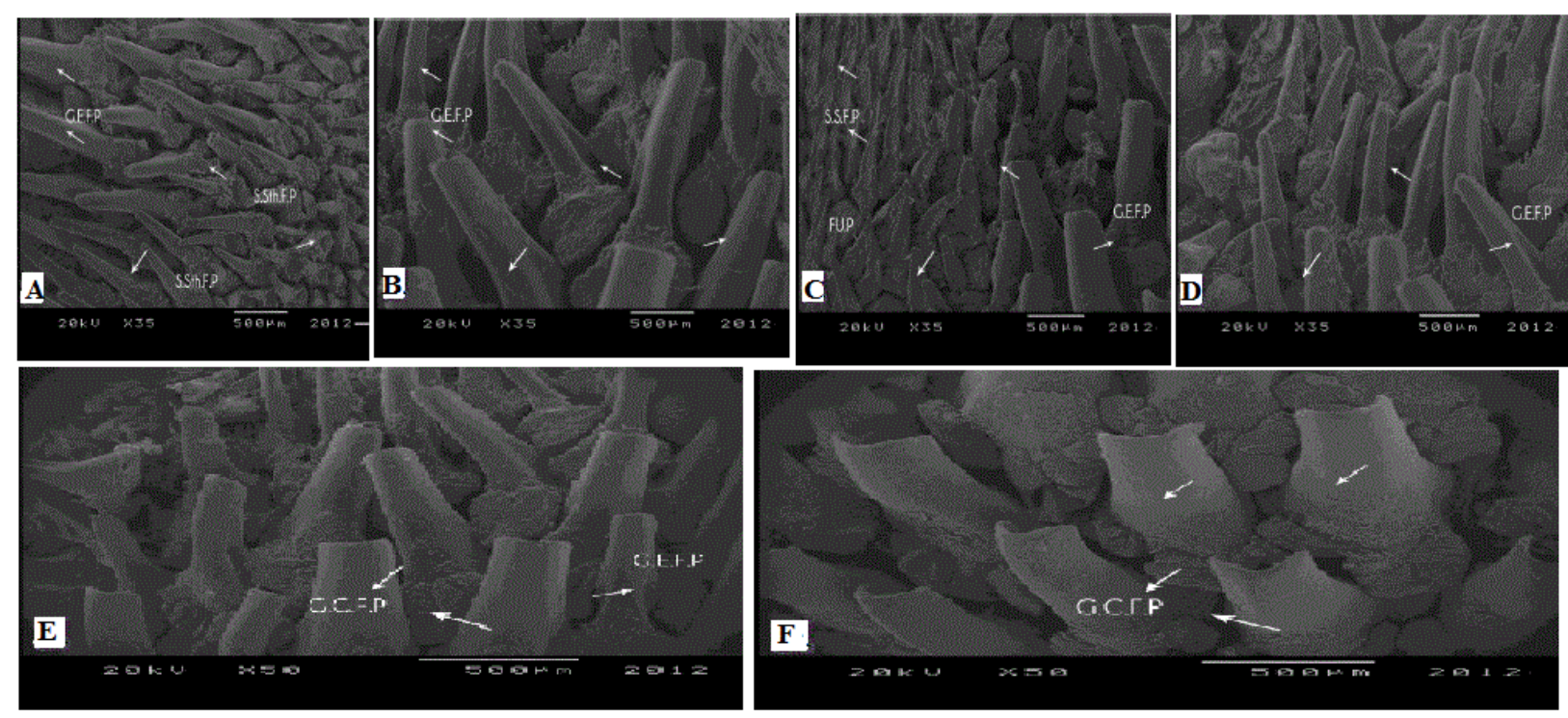

Figure 6: A set of lingual papillae distributed on the anterior middle part of the tongue. A and B, scanning electron micrograph (SEM) showing Giant elongated filiform papillae (G.E.F.P) and small smooth filiform papillae (S.Th. E.P), also show small serrate filiform papillae (S.S.F.P) indicated as arrows were observed and fungiform papillae (Fu. P). C and d. A set of lingual papillae distributed on the posterior middle part of the tongue. E: scanning electron micrograph (SEM) showing Giant conical (G.C.F.P) and giant elongated filiform papillae (G.E.F.P), arrows. F: (SEM) showing higher magnification of conical papillae (G.C.F.P). 

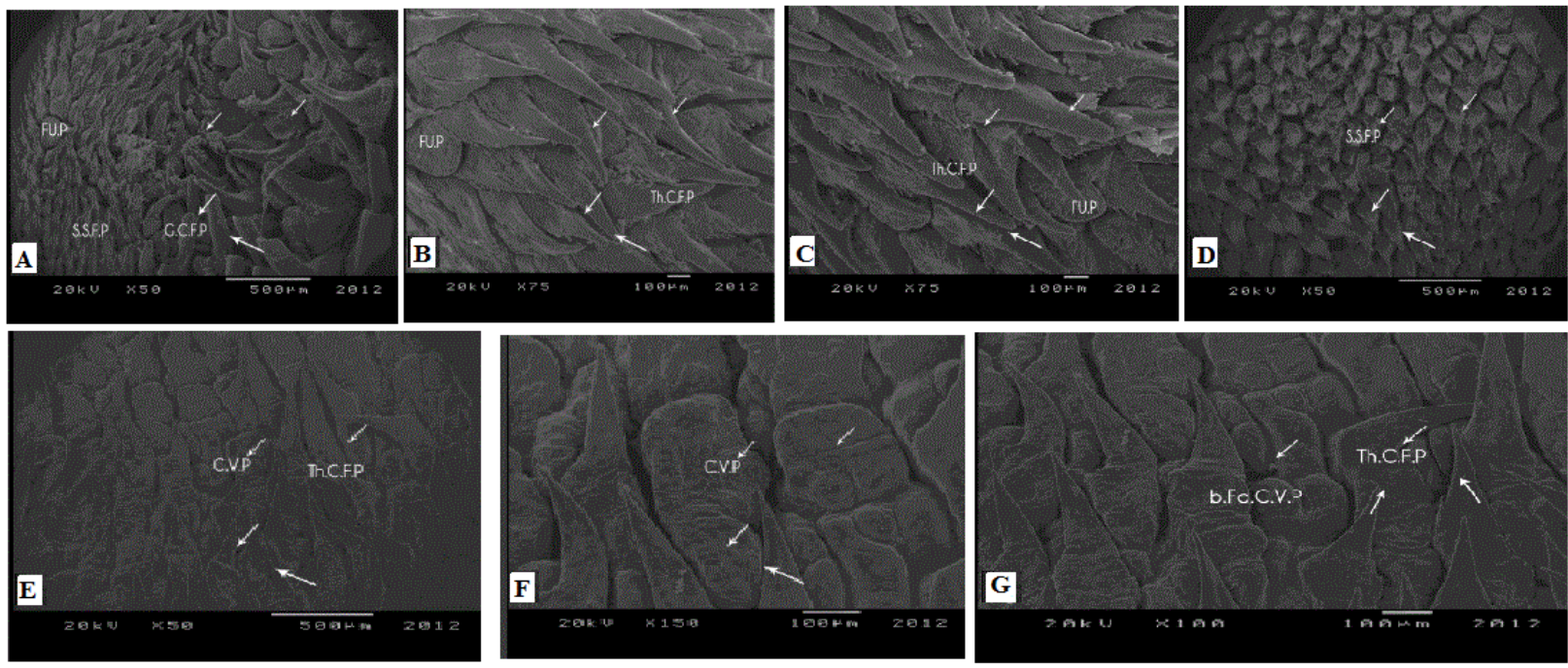

Figure 7: A set of lingual papillae distributed on the posterior root part of the tongue. $a, b$ and d, scanning electron micrograph(SEM) showing the small serrate filiform (S.S.F.P) appear again at the center of the surface Giant conical (G.C.F.P), appear also smooth conical papillae (Th. C.F.P), $b$ and $\mathrm{c}$ with higher magnification. A set of lingual papillae distributed on the posterior root part of the tongue, e. $\mathrm{f}$ and $\mathrm{g}$ scanning electron micrograph (SEM) showing the circumvallate papillae (c. v) and the bifid circumvallate papillae (b, f, d), appear also smooth conical papillae (Th. C.F.P), with higher magnification.

In our observations, there are large giant conical papillae were distributed at the posterior part and the root part of the tongue. In the micrographic report of the Red panda's tongue Emura et al. [20]. Similar cone-like large conical papillae were observed in Japanese badger's which have rather long conical papillae.

Our findings represent that lack of foliate papillae, however the circumvallat papillae found. Many mammals of both terrestrial and aquatic species possess vallate papillae and their distribution varies depending on the species. Ruminants, such as cattle, sheep and goats, possess a number of vallate papillae, 16-34, 18-24 and 12-18, respectively. These vary in size, and form irregular rows on each side of the caudal part of the torus. Pigs and horses have only one pair of very large papillae. The carnivores have four to six Nickel, et al. [21] and Zheng and Kobayashi [22].

\section{Conclusion}

In our observation of the Herpestes ichneumon tongue, large fungiform papillae were distributed in the apex. The large fungiform papillae may be a transitional or incomplete form of vallate papillae. Zheng and Kobayashi [22] assumed that as a result of a proliferation of epithelial cells in the top region of the large fungiform papillae different from the case of bats, the filiform papillae are more distributed mainly at the apex on the dorsum of the tongue, while the fungiform are mainly scattered on the lateral surface and are mostly rounded similar to the case of adult Egyptian Pipistrillus kuhli and the Syrian pipistrillus [23].

The types and the arrangement of the filiform papillae in the Poznan Poland Egyptian fruit eating bat [24] different from both the fruit eating bat and the insectivorous bat in which there are only two subtype of filiform papillae. The occurrence of fungiform papillae in our present animal among the filiform in the posterior part of the tongue may contribute to the taste perception of the food accumulation in this part before swallowing. The distribution of a few number of circumvallate papillae in the form of triangle in the posterior part of the tongue in the present species is similar to other frugivorous species [6,7], others in blood drinking Desmodus rotundus [25].

The present investigation revealed that Herpestes ichneumon tongue basically resembles not only other species of mammals but also have specialized difference characteristics of it which enable it for an adaptation of diet.

\section{References}

1. Mistretta CM (1991) Developmental neurobiology of the taste system. Taste and Smell in Health and Disease TV Getchell. Raven Press, New York, pp: 35-64.

2. Azzali G, Gabbi C, Grandi D, Bonomini D (1991) Morphological and ultra-structural features of the non-sensorypapillae in the tongue of hibernating bats. Arch Ital Anat Embriol 96: 257-280.

3. Pastor JF, Moro JA, Verona JAG, Gatoh Represa JJ, Barbosa E (1993) Morphological study by scanning electron microscopy of the lingual papillae in the common European bat (Pipistrellus pipistrellus). Arch Oral Biol 38: 597-599.

4. Sharman RSK, Vidagadaran MK, Zulkiffil MAJ, Sumita S, Azilah AJ, et al. (1999) Eco morphological implications of the microstructures on the tongue of the rounded leaf Hipposideras Cervinus, Chiroptera: Hipposideridae. Aust J Zool 47: 405-409.

5. Gregorin R (2003) Comparative morphology of the tongue in free tailed bat (Chiroptera, Molossidae). Seria Zool, Iherigia 93: 213-221.

6. Emura S, Hayakawa D, Chen H, Shoumuras A, Agungprjyono S (2001) SEM study on the dorsal lingual surface of the lesser dog-faced fruit bat, Cynopterus brachyotis. Okajimas Folia Anat Jap 78: 123-128.

7. Emura S, Hayakawa D, Chen H, Shoumuras AY, Wijayanto H (2002) SEM study on the dorsal lingual surface of the large flying fox Pteropus vampyrus. Okajimas Folia Anat Jap 79: 113-119. 
Citation: Selim A, Samir R (2018) Light and Scanning Electron Microscope Studies of the Tongue of the Egyptian Mongoose (Herpestes ichneumon). J Cytol Histol 9: 499. doi:10.4172/2157-7099.1000499

Page 6 of 6

8. Kobayashi K, Kumamura M, Yoshimura KM, Takahashi JH, Zeng KK, et al. (2004) Comparative morphological studies on the stero structure of the lingual papillae of selected primates using scanning electron. Annals of anatomy 186: 525-530.

9. Muchhala N (2009) Nectar bat shows huge tongue in its rib cage. Nature 444: 701-709.

10. Kobayashi K, Miyata K, Iwasaki S, Takahashi K (1988) Three dimensional structure of the connective tissue papillae of catlingual papillae. J Ora Biol 30: 719-731.

11. Kobayashi K, Iwasaki S (1989) Comparative studies on the stereo architecture of the connective tissue papillae in some mammalian tongues. In: Motta PM, (ed.) Cell and Tissue: A Three-Dimensional Approach by Modern Techniques on Microscopy. Alan R Liss, pp: 303-308.

12. Yoshiko M, Ken Y, Junji S, Ikuo K (2010) Light and scanning electron microscopic study on the tongue and lingual papillae of the common raccoon Procyon lotor. Okajimas Folia Anat Jpn 87: 65-73.

13. Flynn J, Finarelli JA, Zehr S, Hsu J, Nedbal MA (2005) Molecular phylogeny of the carnivora (mammalia): assessing the impact of increased sampling on resolving enigmatic relationships. Cyst Biol 54: 317-337.

14. Fulton TL, Strobeck C (2006) Molecular phylogeny of the Arctoidea (Carnivora): effect of missing data on super tree and super matrix analyses of multiple gene data sets. Mol Phylogeny Evol 41: 165-181.

15. Bancroft JD, Stevens A (1990) Theory and practice of histological techniques, pp: 43- 80.

16. Gretchen LH (1974) Animal tissue technique (4th edn.).
17. Romeis B (1989) Mikroskopische Technik. Urban and chwarzenberg, Munchen wien Bultimore.

18. Snedecor GW, Cochran WG (1980) The mean and standard deviation. In: Statistical methods (7th ed.) Amer, Lowa, USA. The Lowa Stea University Press, pp: 26-38.

19. Kunz TH, Jones D (2000) Pteropus vampyrus. Mammalian Species, 642: 1-6.

20. Emura S, Okumura T, Chen H (2009) Scanning electron microscopic studies on the lingual papillae and their connective tissue cores of the Lesser panda. Mammal Sci 49: 37-43.

21. Nickel R, Schummer A, Seiferle E (1979) Digestive system. In: Schummer $\mathrm{S}$, Nickel R (2nd revised edn.) The Viscera of the domestic mammals. Verlag Paul Parey, pp: 23-62.

22. Zheng I, Kobayashi K (2006) Comparative morphological study on the lingual papillae and their connective tissue cores (CTC) in reeves' muntjac deer (Muntiacus reevesi). Ann Anat 88: 555-564.

23. Selim A, Nahla NE, Maha S (2008) Comparative anatomical and histological studies of the tongue between the Egyptian bat Pipistrillus kuhli and the Syrian Pipistrillus kuhli. Tishreen University, Journal for Research and Scientific studies-Biological Science Series 30: 247-255.

24. Hanna J, Joanna T, Lorych, Szyman G (2009) The microstructure of lingual papillae in the Egyptian fruit eating bat Rousettus aegyptiacus as observed by Light and electron microscopy. Arch Histol Cytol 72: 13-21.

25. Greenbaum IF, Phillips CJ (1974) Comparative anatomy and general histology of the tongues of long nosed bats Leptonycteris sanboni and L. nivalis with reference to in gestation of oral mites. J mammal 55: 489-504. 